\title{
Long Span Restorations using Zirconia Frameworks
}

\author{
I Azouzi*, I Kalghoum, D Hadyaoui*, B Harzallah and M Cherif \\ Department of Fixed Prosthodontics, University of Monastir, Tunisia
}

Received: 眥 February 12, 2018; Published: 䟱 February 21, 2018

*Corresponding author: I Azouzi, D Hadyaoui, Department of Fixed Prosthodontics, Research Laboratory of Occlusodontics and Ceramic Prostheses LR16ES15, University of Monastir, Tunisia

\begin{abstract}
Porcelain fused to metal restorations have been considered as the gold standard in prosthetic dentistry for a long time thanks to their mechanical properties. However, several drawbacks (light transmission blocked by the metal and the opaque porcelain, metal corrosion phenomenon, gingival tattoo and potential allergic reactions) have limited its use. Recently, all ceramic materials have been introduced in prosthetic dentistry for the fabrication of natural like crowns and fixed partial dentures using CAD/CAM techniques. Zirconia seems to be of great interest thanks to its high esthetics and mechanical characteristics. This article describes, through a clinical report the use of Y-TZP based prostheses in long span fixed partial denture to restore function and esthetics.
\end{abstract}

Keywords: Esthetics; Dentistry; Zirconia

\section{Background}

Porcelain fused to metal restorations has been considered as the gold standard in prosthetic dentistry for a long time thanks to their mechanical properties. However, they have been criticized for their esthetic outcome. In fact, light transmission is blocked by the metal and the opaque porcelain, needed to mask the underlying metal substance causes light reflectivity to rise [1-4]. Metal corrosion phenomenon, gingival tattoo and allergic reactions have also been reported. Patients have always sought for long-lasting and natural like restorations along with metal free materials mimicking the natural dentition [5-7]. To overcome the shortcomings of porcelain fused to metal restorations, advances in dental materials have set the space for the development of allceramic restorations which offer potential excellent esthetics thanks to their optical behavior [8-11]. According to Kelly et al. [12], core translucency is one of the most important factors in meeting esthetic and functional requirements. Other advantage consists in long term stability, excellent biocompatibility and corrosion resistance. Thus, all ceramic restorations integrate well with soft tissues. They guarantee maintenance of gingival health limiting bacterial adhesion accumulation and inflammatory reaction [13].

All-ceramic restorations provide esthetic advantages; their mechanical properties remain unsatisfactory though, thus restricting their clinical indications [14]. Currently, densely sintered zirconia based restorations are of great interest mainly when matched with the appropriate layering ceramic. Zirconia mechanical, optical and biological properties make it a reliable restorative material. Thanks to its unique transformation toughening characteristic, this material can efficiently stop internal crack propagation which improves strength and fracture toughness. Although the low translucency of zirconia is considered as a drawback by some research papers, it is highly recommended in particular clinical situations. Furthermore, advances in computeraided design and manufacturing (CAD/CAM) techniques have significantly improved the restorations marginal fit which met the clinical requirements [15]. For its inherent properties, zirconia seems to be a viable restorative material which can be used as a framework both in anterior and posterior restorations [16]. This paper describes, through a clinical report the use of zirconia based prostheses to replace missing teeth and restore decayed ones. Optimal esthetic outcome in harmony with neighboring teeth and surrounding gingival tissues is attained.

\section{Case Presentation}

A 55-year-old patient was referred to the Fixed Prosthodontics Department of the Dentistry Clinic, University of Monastir. She complained about the poor esthetic of her maxillary anterior teeth. She had a hidden smile and was looking for a prompt solution. Her medical history was non contributory. A meticulous clinical examination was undertaken. Intraoral examination revealed insufficient hygiene resulting in gingivitis and significant substance loss on teeth \#22 and \#23with only cervical residual substance remaining. Overlapping restorations on teeth\#11 and \#12. It 
also revealed defective amalgam restoration on tooth \#15 along with a satisfactory mesio-occlusal restoration on tooth \#25. On probing; we discovered a substance loss on the endoosseous level on tooth \#24. Tooth \#14 was absent (Figures 1-3). Radiographic examination displayed no bone resorption, well-implanted teeth with no peri-apical pathology. Correct crown-root axis abutments together with satisfactory canal treatment on teeth \#11and \#12 and failing endodontic treatment on tooth \#15. The endoosseous substance loss on tooth \#24 was confirmed.

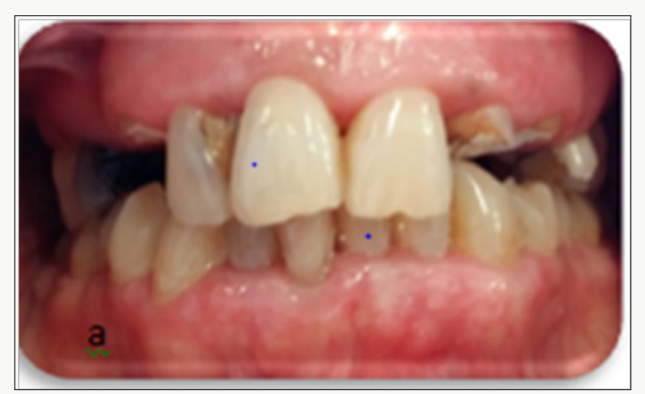

Figure 1: Initial Case: a. Frontal View.

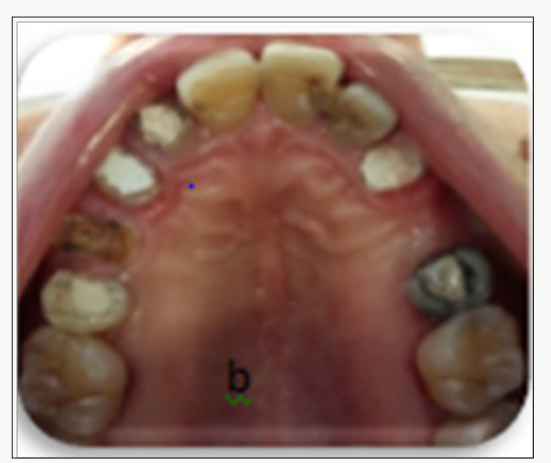

Figure 2: Initial case: b. Occlusal view.
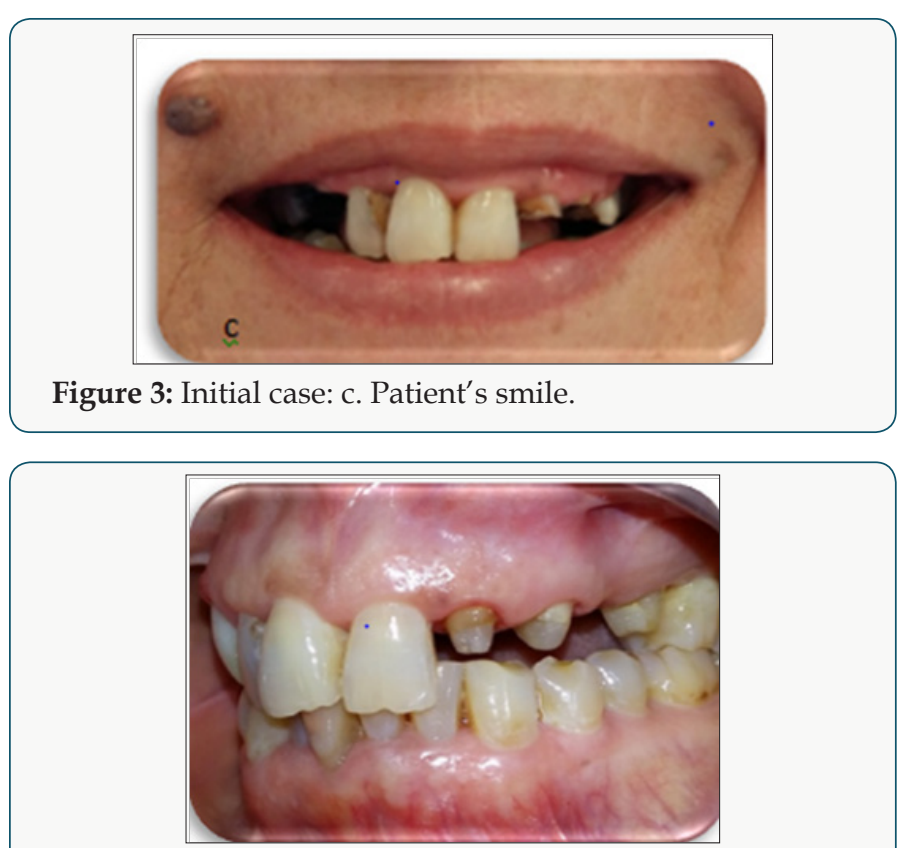

Figure 4: Abutments restored with fiber post and core restorations.
Prior to any prosthetic restoration restorations on teeth \#11 and \#12 were removed in order to release the sepsis and replaced by temporary obturations. Extraction of the tooth \#24 and endodontic retreatment on tooth \#15 were decided. Alginate impressions were done then poured to get study casts. A wax-up was accomplished to previsualize the final esthetic outcome. Several therapeutic options were discussed with the patient, including metal-ceramic and implant-supported restorations. But the fact that she expected an optimal esthetic and wanted to avoid implant surgery explained the selection of an all-ceramic zirconia FPD to replace the missing teeth and restore the decaying ones. Because of the patient's financial limits, hemi-arches were separately restored (Figure 4). So as, a single crown on tooth \#22 and a bridge replacing the \#24 based on the \#23 and the \#25 were first performed. Then the same steps were undertaken to realize two single crowns on teeth \#11 and \#12 as well as a bridge replacing the \#14.Teeth \#22, \#23 and \#25 were priorly restored with fiber posts and resin cores restorations.
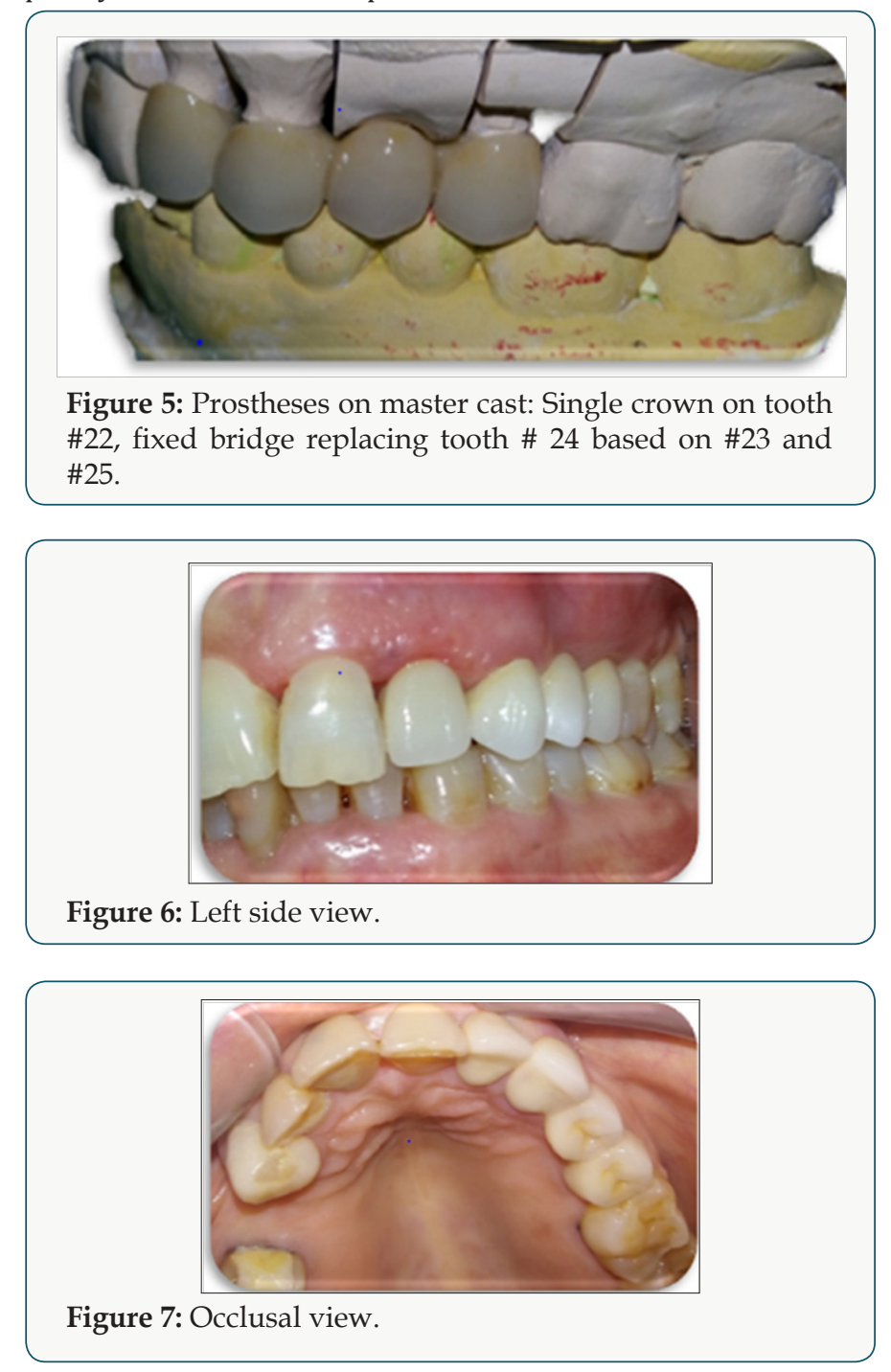

The same steps were followed in both hemi-arches. Abutment teeth were prepared with internal rounded shoulder, subgingivally extended. Due care was taken not to violate the biologic width so as to provide enough space fitting the restorative material 
requirements. It was $2 \mathrm{~mm}$ incisal and occlusal reduction. The axial taper of crown preparation was about 6 degree. Every sharp angle was removed, tooth preparation edges were rounded and margins were smoothened. Provisional restorations were made using the silicone guide index derived from the wax-up, then temporarily cemented. On the following appointment, after careful insertion of the retraction cord, a simultaneous double mixed impression was taken using light and heavy silicon. Impression of the opposing dentition was obtained with alginate. Impressions were sent to the laboratory. There, the mastercast was scanned. Infrastructures were designed and milled by CAD/CAM. Dimensions of the connectors were checked. Clinically, marginal fit was thoroughly assessed. Enough room for appropriate thickness of veneering material was verified. Then, frameworks were returned to the laboratory for veneering with compatible ceramic (Figures 5-7). At the bisque trial, contact surface intensity was checked. Similarly, embrasures were controlled, allowing a correct practice of hygiene habits. Correct pronunciation of the phonemes $(\mathrm{S}, \mathrm{M}, \mathrm{F}, \mathrm{V})$ was assessed. Occlusion was adjusted in intercuspal and excursive positions to allow a functional anterior guide and canine guidance during excentric movements. Once the prostheses were validated, final staining and glazing was conducted to ensure their natural mimicry in harmony with the surrounding dentition. The patient was fully satisfied with the esthetic outcome.

\section{Discussion}

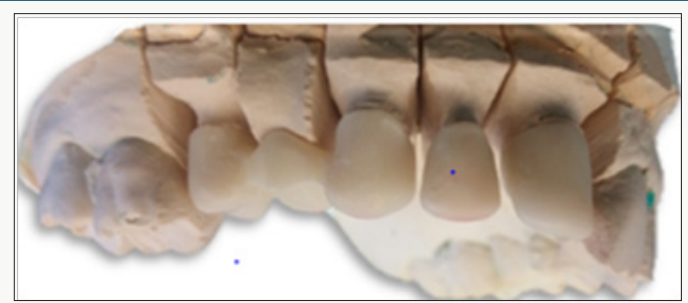

Figure 8: Zirconia frameworks.

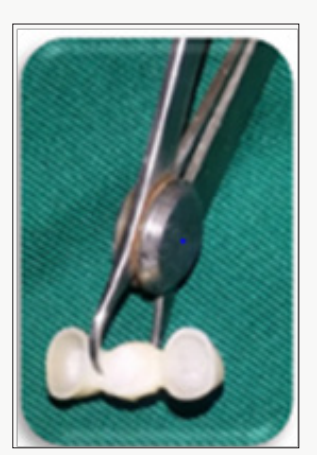

Figure 9: Connector dimensions assessment.

Patient's high esthetic expectations have allowed the emergence of numerous all- ceramic systems with different physical and esthetic properties. But, the practitioner must understand the features of the cited systems to be able to select the appropriate material guaranteeing longevity [4]. Several studies regarding survival and complications of zirconia prosthesis were conducted and published over the last decade. According to Raigdroski et al. [17], survival rates ranged between $73.9 \%$ and $100 \%$. Zirconia based restorations were selected in this case mainly for their mechanical strength and excellent esthetic rendering [18]. As the neighboring teeth were opaque, Y-PSZ was deemed ideal to create natural- like restorations in harmony with adjacent teeth (Figures 8-10). This was confirmed by Heffernan et al. [19] who explained the better suitability of zirconia to the opaque high value teeth.

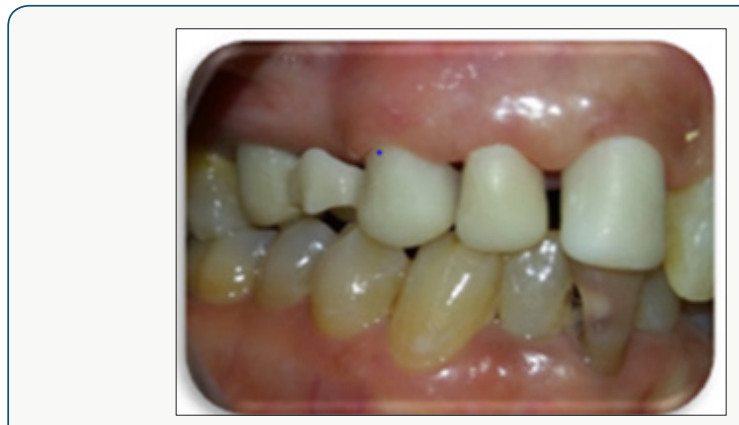

Figure 10: Intra oral trial.

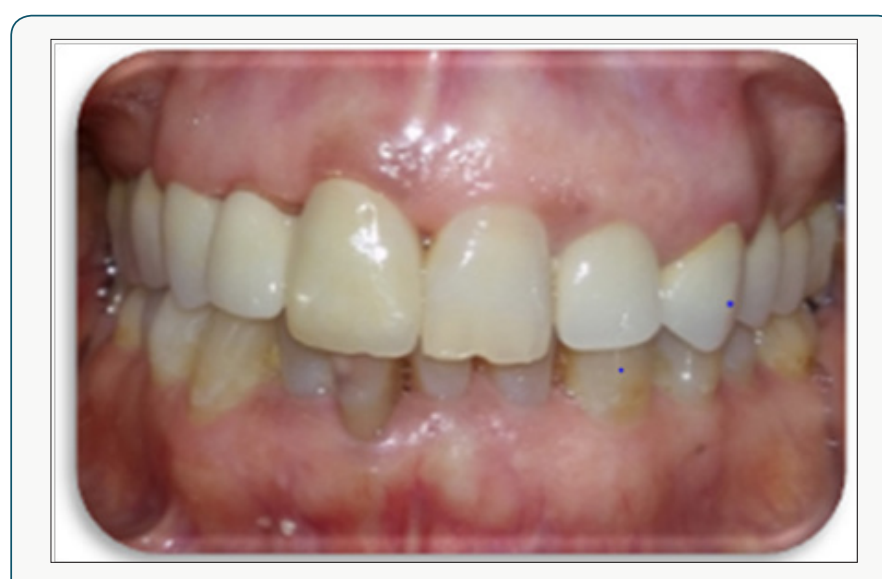

Figure 11: The final result showing zirconia based prostheses in harmony with the neighboring teeth and the surrounding tissues.

One more reason is that finish lines were subgingivally situated, thus, bonding cannot be indicated. Y-PSZ exhibited the highest flexural strength with a range of 900 to $1200 \mathrm{MPa}$. This is approximately 5 times greater than the standard glass ceramics. [20] Its fracture toughness rated from 5 to $10 \mathrm{MP}$ am1/2 [21]. Its elastic modulus is of approximately 200Mpa [22]. Its unique property of martensenic-like transformation can explain its clinical reliability. This transformation can be induced by externally applied tensile stress (Figure 11). It is associated with a volumetric expansion (3\% to $5 \%$ ) of the crystalline structure. Hence, a propagating crack will develop a corresponding stress at its tip, thus preventing continued crack growth [23-25].This helps resist catastrophic failure-even though a crack may exist in the material, the phase changes prevents it from proceeding through the restoration [26]. The high accuracy of fit of these restorations ranges between 0 and $74 \mu \mathrm{m}$ given that accuracy at crown margins of 50 to $100 \mu \mathrm{m}$ is proved to be ideal $[27,28]$. 
This is paramount to ensure a long-term success for dental restorations and avoid recurrent caries or periodontal disease. The mechanical properties of zirconia frameworks are mainly determined by the connectors shape and size. Clinically, insufficient height of these connectors, result in prostheses fractures [29]. To reduce the risk of chipping during and function and ensure longevity, the zirconia infrastructure is properly designed, taking into considerations periodontal soft tissues. In fact, in order to withstand occlusal overloads, flexural strength has to be high enough. It has been proved that the complication risk is more likely to be notable when connector diameters are reduced [30]. Obviously, zirconia framework is originally white. This is considered as a drawback by some authors. However, it is either used to cover discolored dentine or colored to mimic neighboring high value teeth [16]. Besides, through the veneering ceramic, we can rely on the laboratory technician's skill and aesthetic talent to achieve a successful characterization of the restorations. Thus, a deep understanding of zirconia optical properties is required [16].

\section{Conclusion}

Zirconia frameworks created novel perspectives concerning metal free fixed dental reconstructions. They have to be clinically successful. Owing to their levels of various translucency and the ceramic make up. They can offer an optical aesthetic outcome. Since zirconia was introduced, it has witnessed continuous improvements. However, more developments and researches are required to react a-state-of the art level. The veneering porcelain frequent chipping along with the progress of new translucent zirconia ceramics has led to the emergence of full zirconia ceramic restorations.

\section{References}

1. Näpänkangas Ritva, MA Salonen Kemppi, AM Raustia (2002) Longevity of fixed metal ceramic bridge prostheses: a clinical follow-up study. Journal of oral rehabilitation 29(2): 140-145.

2. Näpänkangas R, MA Salonen, AM Raustia (1997) A 10-year followup study of fixed metal ceramic prosthodontics. Journal of oral rehabilitation 24(10): 713-717.

3. Roberts HW, Berzins DW, Moore BK, Charlton DG (2009) Metal-Ceramic Alloys in Dentistry: A Review. Journal of prosthodontics 18(2): 188-194.

4. Anjum Vishwas, Shiromany Aseem (2012) From Non-Esthetic to Esthetic Rehabilitation: A Case Report. Asian Journal of Oral Health and Allied Sciences 2(2): 104-106.

5. Pjetursson BE, Sailer I, Zwahlen M, Hämmerle CH (2007) A systematic review of the survival and complication rates of all-ceramic and metalceramic reconstructions after an observation period of at least 3 years. Part I: Single crowns. Clinical Oral Implants Research 18(Suppl. 3): 7385.

6. Irena Sailer, Bjarni E Pjetursson, Marcel Zwahlen, Christoph HF Hammerle (2007) A systematic review of the survival and complication rates of allceramic and metal-ceramic reconstructions after an observation period of at least 3 years. Part II: fixed dental prostheses. Clinical Oral Implants Research 18(Suppl. 3): 86-96.

7. Hosoki Maki, Keisuke Nishigawa (2011) Dental metal allergy. Contact Dermatitis.
8. Manicone Paolo Francesco, Pierfrancesco Rossi Iommetti, Luca Raffaelli (2007) An overview of zirconia ceramics: basic properties and clinical applications. Journal of dentistry 35(11): 819-826.

9. Raut A, Rao PL, Ravindranath $T$ (2011) Zirconium for esthetic rehabilitation: An overview. Indian Journal of Dental Research 22(1): 140-143.

10. Polack, Mariano A (2006) Restoration of maxillary incisors with a zirconia all-ceramic system: A case report. Quintessence international 37(5): 375-380.

11. Ashby Michael F (2005) Materials Selection in Mechanical Design.

12. Kelly JR, Nishimura I, Campbell SD (1996) Ceramics in dentistry: Historical roots and current perspectives. The Journal of Prosthetic Dentistry 75(1): 18-32.

13. Manicone PF, Rossi Iommetti P, Raffaelli L, Paolantonio M, Rossi G, et al. (2007) Biological considerations on the use of zirconia for dental devices. International journal of immunopathology and pharmacology 20 (suppl 1): $9-12$.

14. Manicone Paolo Francesco, Pierfrancesco Rossi Iommetti, Luca Raffaelli (2007) An overview of zirconia ceramics: basic properties and clinical applications. Journal of dentistry 35(11): 819-826.

15. Raigrodski, Ariel J (2014) Managing Prosthetic Challenges with a CAD/ CAM Zirconia Restoration. Journal of Cosmetic Dentistry 30(2): 40-52.

16. Lee Culp, Lida Swann (2018) Zirconia's Esthetic Evolution. Journal of dental technology: 28-34.

17. Raigrodski Ariel J, Hillstead MB, Meng GK, Chung KH (2012) Survival and complications of zirconia-based fixed dental prostheses: a systematic review. The Journal of prosthetic dentistry 107(3): 170-177.

18. Vagkopoulou T, Koutayas SO, Koidis P, Strub JR (2009) Zirconia in dentistry part I: Discovering the nature of an upcoming bioceramic. The European Journal of Esthetic Dentistry 4(2):s 130-151.

19. Heffernan MJ, Aquilino SA, Diaz Arnold AM, Haselton DR, Stanford CM, et al. (2002) Relative translucency of six all-ceramic systems. Part II: Core and veneer materials. The Journal of Prosthetic Dentistry 88(1): 10-15.

20. Christel P, Meunier A, Heller M, Torre JP, Peille CN (1989) Mechanical properties and short-term in-vivo evaluation of yttrium-oxide-partiallystabilized zirconia. Journal of Biomedical Materials Research 23(1): 4561.

21. Daou EE (2014) The Zirconia Ceramic: Strengths and Weaknesses. The Open Dentistry Journal 8: 33-42.

22. Guazzato M, Albakry M, Ringer SP, Swain MV (2004) Strength, fracture toughness and microstructure of a selection of all-ceramic materials: Part II: Zirconia-based dental ceramics. Dental Materials 20(5): 449-456.

23. Madfa Ahmed A, Fadhel A Al Sanabani, Nasser H Al Qudami, Jabr S Al Sanabani, Abdullah G Amran (2014) Use of zirconia in dentistry: an overview. The Open Biomaterials Journal 5(1): 1-9.

24. Pilathadka S, D Vahalová, T Vosáhlo (2007) The Zirconia: a new dental ceramic material. An overview. Prague Medical Report 108(1): 5-12.

25. Porter DL, AG Evans, AH Heuer (1979) Transformation-toughening in partially-stabilized zirconia (PSZ). Actametallurgica 27(10): 1649-1654.

26. Papanagiotou HP, Morgano SM, Giordano RA, Pober R, et al. (2006) In vitro evaluation of low-temperature aging effects and finishing procedures on the flexural strength and structural stability of Y-TZP dental ceramics. Journal of Prosthetic Dentistry 96(3): 154-164.

27. Elie Daou, Maha Al Gotmeh (2014) Zirconia Ceramics: A versatile restorative material. Dentistry 4: 4 . 
28. Fernando Zarone, Russo S, Sorrentino R (2011) From porcelain fused to metal to zirconia: Clinical and experimental considerations. Dental Materials 27(1): 83-96

29. Zarone Fernando, Simona Russo, Roberto Sorrentino (2011) From porcelain-fused-to-metal to zirconia: clinical and experimenta considerations. Dental materials 27(1): 83-96.
30. Schmitter M, Mussotter K, Rammelsberg P, Gabbert O, Ohlmann B (2012) Clinical performance of long-span zirconia frameworks for fixed dental prostheses: 5-year results. Journal of oral rehabilitation 39(7): 552-557.

\section{(C) \\ This work is licensed under Creative Commons Attribution 4.0 License}

To Submit Your Article Click Here:

Submit Article

DOI: $10.32474 /$ MADOHC.2018.01.000113

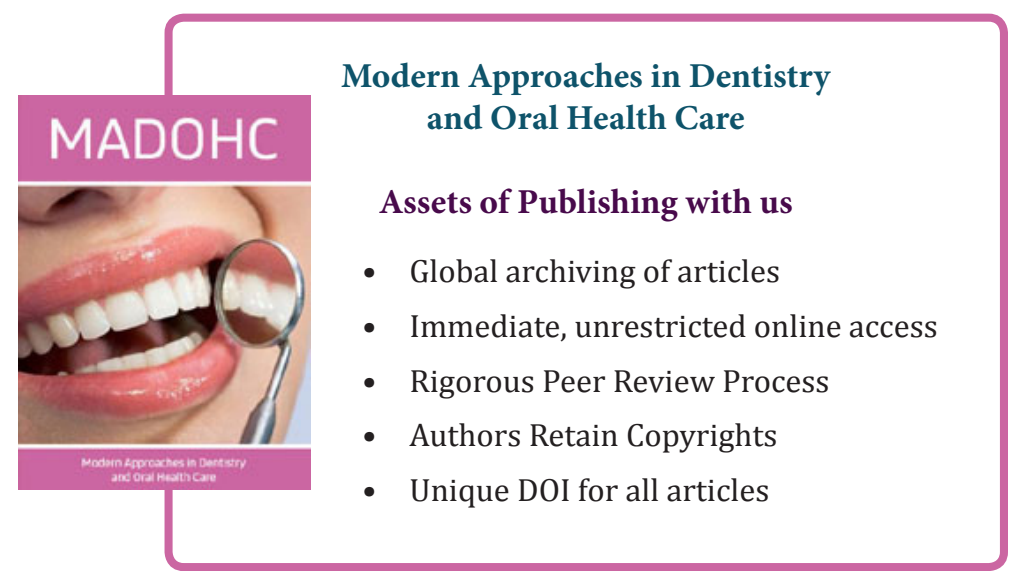

